\title{
Erratum to: An approach to interpretation of step drawdown tests
}

\author{
Shashank Shekhar
}

Erratum to: Hydrogeology Journal (2006), 14: 1018-1027 DOI 10.1007/s10040-005-0016-x

There are errors in Table 4 of the original article, specifically for Dd (column 4), B.L Asmptn1 (column 5) and Re-1 Asmptn1 (column 8).

The correct version of Table 4 is given below.

In the original article, Table 4 presents Reynold's number at different entrance velocities and at different discharge levels. The Reynold's number in the original Table 4 was calculated using the formula:

$\begin{aligned} R e= & (\text { density of fluid } \times \text { magnitude of its velocity } \times \text { boundary to fluid flow }) / \\ & \text { viscosity of fluid }\end{aligned}$

The work used two approaches for fixing the boundary to fluid flow. In the first approach the boundary to fluid flow was assumed to be length from the well bottom to the pumping water level. The second approach was based on the assumption of the

Published online: 16 February 2011

(C) Springer-Verlag 2011

The online version of the original article can be found at http://dx. doi.org/10.1007/s10040-005-0016-x.

\section{S. Shekhar $(\square)$}

Department of Geology,

University of Delhi, Delhi 110007, India

e-mail: shashankshekhar01@gmail.com

Tel.: +91-11-9212600385

boundary length being the total length of the screen (See section Calculation of Reynold's number on page 1022). There is no error with the calculations related to the second approach but there are errors related to the first approach mentioned above.

Firstly the drawdown values (Dd) in column 4 of the original Table 4 do not match with the observed drawdown values in column 2 of the original Table 2 . There were some errors in copying values from Table 2 to the corresponding column in Table 4 . Thus, in this Erratum the correct values of drawdown (Dd), as given in Table 2 of the original article, have been put in Table 4. Since B.L Asmptn1 (column 5) and Re-1 Asmptn1 (column 8) values are a function of drawdown (Dd), they also change.

There was another small error in calculation of B.L Asmptn1 (column 5), which was calculated using the formula:

$$
\begin{aligned}
\text { B. L Asmptn1 }(\text { column 5) }= & \text { Depth of well construction } \\
& -(\text { initial water level }+ \text { drawdown })
\end{aligned}
$$

The initial depth to water level was mentioned as $4.22 \mathrm{~m}$ below ground level (mbgl) (see section Experimentation in the original article, page1019). The position of the last slotted pipe was given as 39.5-43.5 mbgl. The tubewell design has $3 \mathrm{~m}$ of blank pipe with conical bottom following the last slotted pipe. This gives depth of well construction as $46.5 \mathrm{mbgl}$. So, while calculating the values of B.L Asmptn1 (column 5) for Table 4 of the original article, only drawdown (Dd) was subtracted from the depth of well construction values. Instead, a sum of initial water level and drawdown (Dd) should have been subtracted. This error in the calculation has also been rectified. 
Table 4 Reynold's number at different entrance velocities and at different discharge levels

\begin{tabular}{lllllllll}
\hline Steps & E. Vel $(\mathrm{m} / \mathrm{s})$ & $\begin{array}{l}\text { Density } \\
\left(\mathrm{kg} / \mathrm{m}^{3}\right)\end{array}$ & Dd $(\mathrm{m})$ & $\begin{array}{l}\text { B.L }(\mathrm{m}) \\
\text { Asmptn 1 }\end{array}$ & $\begin{array}{l}\text { B.L }(\mathrm{m}) \\
\text { Asmptn 2 }\end{array}$ & $\begin{array}{l}\text { Viscosity } \\
\left(\mathrm{N} \mathrm{s} / \mathrm{m}^{2}\right)\end{array}$ & $\begin{array}{l}R e-1 \\
\text { Asmptn 1 }\end{array}$ & $\begin{array}{l}R e-2 \\
\text { Asmptn 2 }\end{array}$ \\
\hline 1 & 0.00349 & 1000 & 5 & 37.28 & 14 & 0.001 & 130107 \\
2 & 0.00385 & 1000 & 6.1 & 36.18 & 14 & 0.001 & 139293 \\
3 & 0.00424 & 1000 & 6.9 & 35.38 & 14 & 0.001 & 150011 \\
4 & 0.00456 & 1000 & 7.45 & 34.83 & 14 & 0.001 & 158825 \\
5 & 0.00483 & 1000 & 8.05 & 34.23 & 14 & 0.001 & 165331 \\
6 & 0.0051 & 1000 & 8.5 & 33.78 & 14 & 0.001 & 63800 \\
&
\end{tabular}

E. Vel - entrance velocity, B.L - boundary length, $R e$ - Reynold's number, Asmptn - assumption, Dd - drawdown, Ns $/ \mathrm{m}^{2}-\mathrm{Newton}$ seconds per $\mathrm{m}^{2}$ 